\title{
EDITORIAL
}

\section{Identity of mysterious $\mathrm{CD} 4^{+} \mathrm{CD} 25^{-}{ }^{-}$oxp $3^{+}$cells in systemic lupus erythematosus}

\author{
David A Horwitz* \\ See related research by Yang et al., http://arthritis-research.com/content/11/5/R153
}

\begin{abstract}
Various abnormalities in $\mathrm{CD} 4^{+} \mathrm{CD} 25^{+}$regulatory $T$ cells (Tregs) in systemic lupus erythematosus (SLE) include increased Foxp3 ${ }^{+}$cells that are CD25 negative. Barring methodological technical factors, these cells could be atypical Tregs or activated non-Treg CD4+ cells that express Foxp3. Two groups have reached opposite conclusions that could possibly reflect the subjects studied. One group studied untreated new-onset SLE and suggested that these T cells were mostly CD25-Foxp3 ${ }^{+}$non-Tregs. The other group studied patients with long-standing disease and suggested that these cells are mostly dysfunctional Tregs. A third group reported increased Foxp $3^{+} C D 4^{+} C D 25^{\text {dim }}$ rather than $\mathrm{CD}_{25}{ }^{-}$cells in active SLE and these were also non-Tregs. Thus, it is likely that not all Foxp $3^{+} T$ cells in SLE have protective suppressive activity.
\end{abstract}

Abnormalities of $\mathrm{CD}^{+}{ }^{+} \mathrm{CD} 25^{+}{ }^{+}$oxp $3^{+}$regulatory $\mathrm{T}$ cells (Tregs) probably contribute to $\mathrm{T}$ - and B-cell hyperactivity in systemic lupus erythematosus (SLE), but reports on numbers and function of these cells in this autoimmune disease have been contradictory. Studies on circulating $\mathrm{CD} 4^{+}$cells in SLE which express Foxp3, the transcription factor that generates these cells, have been inconsistent. Various groups have reported decreased, normal, or even increased numbers. Another problem is that, in humans, Foxp3 cannot be used as a marker of Tregs as activated $\mathrm{CD}^{+}$non-Tregs can transiently express Foxp3. Finally, although $\mathrm{CD} 4^{+}$cells that stain brightly for $\mathrm{CD} 25$ are Tregs, many $\mathrm{CD} 4^{+} \mathrm{Foxp} 3^{+}$cells in human SLE are CD25 $5^{\text {low }}$

*Correspondence: dhorwitz@usc.edu

Division of Rheumatology, Department of Medicine, University of Southern California, Keck School of Medicine, 2011 Zonal Avenue, HMR 711, Los Angeles, CA 90033, USA or $\mathrm{CD}^{2} 5^{-}$, and their identity is poorly defined. Two groups that reported increased percentages of $\mathrm{CD} 4{ }^{+} \mathrm{CD} 25^{-}$ Foxp $^{+}$cells in SLE have recently tried to characterize these cells but reached different conclusions. A report by Yang and colleagues [1] was recently published in this journal and another by Bonelli and colleagues [2] was published elsewhere. Here, we discuss the essence of the controversy and approaches to resolve it. A more complete review of Tregs in SLE has also been published in this journal [3].

The report by Yang and colleagues [1] was preceded by one in which this group studied subjects with untreated new-onset SLE and reported increased percentages of CD4 ${ }^{+} \mathrm{CD} 25^{-}$Foxp $^{+}$cells that were also CD127 ${ }^{\text {low }}[4]$. Differences in the intensity of CD127 staining are useful to distinguish $\mathrm{CD} 4^{+}$Tregs from $\mathrm{CD} 127^{\text {bright }}$ non-Tregs [5] and suggested that the CD25-Foxp $3^{+}$cells were Tregs. However, this group also reported that the prevalence of these cells positively correlated with the titer of antidouble-stranded DNA antibodies and that these cells decreased in most patients with active lupus after effective treatment [4]. This finding suggested that the CD25-Foxp $3^{+}$cells were previously activated non-Tregs. Because of these conflicting observations, they conducted a new study, and the report by Yang and colleagues [1] was published in a recent issue of this journal.

These workers again studied new-onset SLE and found that the phenotype of $\mathrm{CD} 4{ }^{+} \mathrm{CD} 25^{-} \mathrm{Foxp}^{+}$cells differed from that of typical Tregs. These CD25-Foxp $3^{+}$cells also produced more interleukin-2 (IL-2) and other cytokines than $\mathrm{CD} 25^{\text {high }} \mathrm{Foxp}^{+}$cells did. Studies investigating the value of CD127 as a surrogate marker of Foxp3 revealed that although most CD25-Foxp $3^{+}$cells were CD127 dim or $\mathrm{CD}^{2} 7^{-}$, only $9 \%$ of $\mathrm{CD} 25^{-} \mathrm{CD} 127^{\text {low/- }}$ cells were Foxp3 ${ }^{+}$. Therefore, the authors concluded that CD127 is not an appropriate marker for intracellular Foxp3 in CD4+CD25cells. Studies of suppressor function in vitro revealed that the CD25-CD127 dim/- subset completely lacked suppressive activity. By contrast, $\mathrm{CD} 25^{\mathrm{dim}} \mathrm{CD} 127^{\text {low/ }}$ cells suppressed T-cell proliferation though not as well as the $\mathrm{CD} 25^{\text {high }} \mathrm{CD} 127^{\text {low } /-}$ subset. Thus, they concluded that 
$\mathrm{CD}^{+} \mathrm{CD} 25^{-} \mathrm{Foxp}^{+}{ }^{+}$in untreated new-onset lupus patients lacked the phenotype and functional activity of Tregs.

Instead of studying new-onset subjects, Bonelli and colleagues [2] studied patients with SLE, rheumatoid arthritis, or systemic sclerosis who were drawn from the authors' outpatient clinics and found increased percentages of $\mathrm{CD}^{+}{ }^{+} \mathrm{CD} 25^{-} \mathrm{Foxp}^{+}$cells in SLE only. Their phenotypic profile included $\mathrm{CD} 127^{\text {low }}$ and was consistent with the cells being Tregs rather than T-effector cells. These workers isolated $\mathrm{CD} 4{ }^{+} \mathrm{CD} 25^{-} \mathrm{CD} 127^{-}$cells by fluorescence-activated cell sorting and found that the cells contained up to 53\% Foxp3 ${ }^{+} \mathrm{T}$ cells. Functional studies revealed that these cells suppressed T-cell proliferation but not production of interferon-gamma, a suppressor T-cell abnormality also described in rheumatoid arthritis [6]. Because of phenotypic and functional similarities to typical Tregs, the authors concluded that $\mathrm{CD}^{+}{ }^{+} \mathrm{CD} 25^{-}$Foxp $^{+} \mathrm{T}$ cells in SLE were dysfunctional Tregs.

Thus, whereas Yang and colleagues [1] concluded that most $\mathrm{CD}^{+}{ }^{+} \mathrm{CD} 25^{-}{ }^{-}$oxp $^{+}$cells in SLE are probably previously activated conventional $\mathrm{T}$ cells, Bonelli and colleagues [2] suggested that they are dysfunctional Tregs. The strengths of the argument of Yang and colleagues are the phenotypic differences, the presence of cells producing IL-2 and other cytokines, the lack of suppressive activity, and the fact that fewer than $10 \%$ of $\mathrm{CD} 4^{+} \mathrm{CD} 25^{-} \mathrm{CD} 127^{\text {low/- }}$ cells expressed Foxp3. The strengths of the argument of Bonelli and colleagues [2] include the fact that more than $30 \%$ of $\mathrm{CD} 4{ }^{+} \mathrm{CD} 25^{-} \mathrm{CD} 127^{\text {low/ }}$ cells expressed Foxp3, the lack of proliferative potential, the lack of cytokine-producing cells, and the ability to suppress T-cell proliferation in vitro. The different conclusions of the two groups can possibly be explained by the groups of lupus patients studied. One studied untreated newly diagnosed subjects, whereas the other studied treated individuals with less active disease. It is certainly possible that the CD25-Foxp $3^{+}$cells reflect different populations, depending upon when the subjects were studied.

A remaining important question is the reason why these cells are $\mathrm{CD}^{2} 5^{-}$. Both Tregs and activated CD4 ${ }^{+}$ cells generally express CD25. Miyara and colleagues [7] recently characterized $\mathrm{CD}^{+}{ }^{+} \mathrm{Foxp}^{+}{ }^{+}$cells and divided them into three distinctive populations based upon CD45RA expression and intensity of CD25 staining. These included naïve CD45RA ${ }^{+} \mathrm{CD} 25^{\text {moderate }}$ Foxp $3^{\text {lo }}$ Treg resting precursor cells that, when activated, become CD45RA-CD25 ${ }^{\text {high }}$ Foxp $3^{\text {hi }}$ Treg effector cells. The third population consisted of CD45RA-CD25 ${ }^{\text {dim }} F o x p 33^{\text {lo }}$ nonTregs. Interestingly, in patients with active disease, these workers reported increased proportions of $\mathrm{CD} 4^{+} \mathrm{Foxp}^{3}$ non-Tregs which decreased as the disease became less active. They did not find CD4 ${ }^{+} \mathrm{CD} 25^{-}$Foxp $3^{+}$cells in SLE. The $\mathrm{CD} 4{ }^{+} \mathrm{CD} 25^{-}$cells described by Bonelli and colleagues
[2] were mostly Foxp $3^{\text {lo }}$. Therefore, if these cells were also $\mathrm{CD}_{4} \mathrm{RA}^{-}$, they would be similar to the $\mathrm{CD}^{+}{ }^{+} \mathrm{Foxp}^{+}{ }^{+}$nonTregs described by Miyara and colleagues [7] and the difference between the two studies would be the staining intensity of the anti-CD25 conjugate used.

Another method to distinguish $\mathrm{CD}^{+}{ }^{+} \mathrm{Foxp}^{+}{ }^{+}$Tregs from non-Tregs would be to examine the stability of Foxp3 expressed by these cells in culture. As stated above, Foxp3 expressed by Tregs is relatively stable whereas that of non-Tregs is not [8]. Finally, activated Tregs display membrane-bound transforming growth factor-beta [9] and LAP (latency-associated protein) [10]. To convincingly show that a given subset has regulatory rather than effector function, one should demonstrate suppressor cell activity in vivo in an animal model as described by Hippen and colleagues [11] with human cord blood $\mathrm{CD} 4{ }^{+} \mathrm{CD} 25^{+}$cells.

Abbreviations

$\mathrm{IL}-2$ = interleukin-2; SLE = systemic lupus erythematosus; Treg = regulatory T cell.

\section{Competing interests}

DAH is a consultant for Becton Dickinson Biosciences, San Jose, California.

Published: 20 January 2010

\section{References}

1. Yang HX, Zhang W, Zhao LD, Li Y, Zhang FC, Tang FL, He W, Zhang X: Are CD4+CD25-Foxp3+ cells in untreated new-onset lupus patients regulatory T cells? Arthritis Res Ther 2009, 11:R153.

2. Bonelli M, Savitskaya A, Steiner CW, Rath E, Smolen JS, Scheinecker C: Phenotypic and functional analysis of CD4+ CD25- Foxp3+ T cells in patients with systemic lupus erythematosus. J Immuno/ 2009, 182:1689-1695.

3. Horwitz DA: Regulatory T cells in systemic lupus erythematosus: past, present and future. Arthritis Res Ther 2008, 10:227.

4. Zhang B, Zhang X, Tang F, Zhu L, Liu Y, Chen W, Lipsky P: Clinical significance of increased CD4+CD25-Foxp3+T cells in patients with new-onset systemic lupus erythematosus. Ann Rheum Dis 2008, 67:1037-1040.

5. Liu W, Putnam AL, Xu-Yu Z, Szot GL, Lee MR, Zhu S, Gottlieb PA, Kapranov P, Gingeras TR, Fazekas de St Groth B, Clayberger C, Soper DM, Ziegler SF, Bluestone JA: CD127 expression inversely correlates with FoxP3 and suppressive function of human CD4+ T reg cells. J Exp Med 2006, 203:1701-1711.

6. Nadkarni S, Mauri C, Ehrenstein MR: Anti-TNF-alpha therapy induces a distinct regulatory $T$ cell population in patients with rheumatoid arthritis via TGF-beta. J Exp Med 2007, 204:33-39.

7. Miyara M, Yoshioka Y, Kitoh A, Shima T, Wing K, Niwa A, Parizot C, Taflin C, Heike T, Valeyre D, Mathian A, Nakahata T, Yamaguchi T, Nomura T, Ono M, Amoura Z, Gorochov G, Sakaguchi S: Functional delineation and differentiation dynamics of human CD4+ T cells expressing the FoxP3 transcription factor. Immunity 2009, 30:899-911.

8. Gavin MA, Torgerson TR, Houston E, DeRoos P, Ho WY, Stray-Pedersen A, Ocheltree EL, Greenberg PD, Ochs HD, Rudensky AY: Single-cell analysis of normal and FOXP3-mutant human T cells: FOXP3 expression without regulatory T cell development. Proc Natl Acad Sci U S A 2006, 103:6659-6664.

9. Nakamura K, Kitani A, Fuss I, Pedersen A, Harada N, Nawata H, Strober W: TGF-beta 1 plays an important role in the mechanism of CD4+CD25+ regulatory T cell activity in both humans and mice. J Immuno/ 2004 , 172:834-842.

10. Belkaid $Y$, Tarbell $\mathrm{K}$ : Regulatory $T$ cells in the control of host-microorganism interactions (*). Annu Rev Immunol 2009, 27:551-589.

11. Hippen KL, Harker-Murray P, Porter SB, Merkel SC, Londer A, Taylor DK, Bina M, Panoskaltsis-Mortari A, Rubinstein P, Van Rooijen N, Golovina TN, Suhoski MM, 
Miller JS, Wagner JE, June CH, Riley JL, Blazar BR: Umbilical cord blood regulatory T-cell expansion and functional effects of tumor necrosis factor receptor family members OX40 and 4-1BB expressed on artificial antigenpresenting cells. Blood 2008, 112:2847-2857. doi:10.1186/ar2894

Cite this article as: Horwitz DA: Identity of mysterious $\mathrm{CD}^{+} \mathrm{CD} 25^{-}$Foxp3 $3^{+}$cells in SLE. Arthritis Research \& Therapy 2010, 12:101. 